\title{
Correlations between the Total Antioxidant Activity and Biochemical Parameters of Cow Milk Depending on the Number of Somatic Cells
}

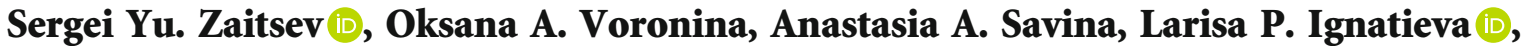 \\ and Nadezhda V. Bogolyubova
}

Federal Research Center for Animal Husbandry named after Academy Member L.K. Ernst, Dubrovitsy 60, Podolsk Municipal District, Moscow Region 142132, Russia

Correspondence should be addressed to Sergei Yu. Zaitsev; s.y.zaitsev@mail.ru

Received 8 July 2021; Revised 4 November 2021; Accepted 15 November 2021; Published 13 January 2022

Academic Editor: Parise Adadi

Copyright (c) 2022 Sergei Yu. Zaitsev et al. This is an open access article distributed under the Creative Commons Attribution License, which permits unrestricted use, distribution, and reproduction in any medium, provided the original work is properly cited.

\begin{abstract}
The aim of the work was to study the correlations between the total amount of water-soluble antioxidants (TAWSA) and biochemical parameters (BC) of cow milk depending on the somatic cell count (SCC). The BC and TAWSA values of cow milk were measured by spectroscopic and amperometric methods, respectively. The milk samples from the black-and-white cows (Moscow region) were divided according to SCC values: (1) $\leq 200$, (2) 200-499, (3) 500-999, and (4) $\geq 1000$ thousand units $/ \mathrm{mL}$. The average TAWSA values for groups $1,2,3$, and $4(33,15,13$, and 12 milk samples) were the following: $15.95 \pm$ $0.74,14.45 \pm 0.84,16.04 \pm 0.63$, and $14.58 \pm 1.18$. The correlations between TAWSA and BC (group 1) were the following: total fat percentage (TFP) -0.305 ; true protein percentage (TP1) -0.197 ; total nitrogen percentage (TN2) -0.210 ; lactose -0.156 ; solids-not-fat (SNF) -0.276; total dry matter (TDM) -0.399; freezing point (FP) -0.112; pH -0.114; somatic cell count (SCC) $(-0,052)$. The correlations between TAWSA and BC (group 2) were the following: TFP -0.332; TP1 -0.296; TN2 -0.303; lactose - (-0.308); SNF -0.159; TDM -0.391; FP -0.226; pH - (-0.211); SCC -0.193. The correlations between TAWSA and BC (group 3) were the following: TFP - (-0.352); TP1 - (-0.411); TN2 - (-0.401); lactose - $(-0.166)$; SNF - (-0.462); TDM - (-0.504); FP $(-0.766) ; \mathrm{pH}-(-0.047)$; SCC - (-0.698). The correlations between TAWSA and BC (group 4) were the following: TFP -0.159; TP1 -0.046; TN2 - 0.077; lactose - (-0.317); SNF - (-0.237); TDM -0.058; FP - (-0.036); pH - (-0.477); SCC - (-0.072). These data are important in assessing the physiological-biochemical status and state of the antioxidant defense system of cows' organism.
\end{abstract}

\section{Introduction}

Milk is an important biological fluid and intensively studied in many aspects: from fundamental interfacial problems (of such complex colloid system) to the properties and quality of milk production. A comprehensive analysis of the biochemical properties of animal milk should include the study of the antioxidant activity (AOA) of such animal fluids, which is associated with the formation of reactive oxygen species (ROS). It is well known that ROS are formed during many metabolic processes in biological fluids, having a negative effect on the main biologically active compounds (BAC), on organs and tissues, etc. [1-3]. There are many reasons for the high interest in the study of the total amount of water-soluble antioxidants (TAWSA) as indicators of the antioxidant defense system against ROS. For example, the AOA data are a valuable source of information "on the state of health and the level of stress resistance of humans and productive animals in a farm environment" [4]. This is due to the search for "functional products" in the system of "antioxidant nutrition" in humans and in animal feeding [4]. Such attention to the study of the antioxidant defense system has led to development a few methods for studying its work [5-7]. 
Here, we will focus only on the electrochemical method, which is associated with the amperometric detection of the oxidation reaction signal [5-7], because we are not being able to list all known methods for studying AOA and biochemical parameters of cow milk. Amperometric detection is widely used as one of the reliable, available, and easy-touse methods for the determination of antioxidants [5-7]. It is well known that the magnitude of the electric current depends on the nature of the "analyte," the material of the working electrode, the potential applied to the electrode, etc. [5-7]. The sensitivity of the amperometric detector is very high due to low noise levels, of the order of 10-12 A [5-7]. Methods and approaches to the determination and analysis of the main biochemical parameters of cows' milk are described in a large number of works (only a few of which will be cited here [8-11]). In addition, the main of these modern methods is included in the corresponding Russian state standards (GOST) and technical requirements (TR) [12-14].

According to the requirements of the technical regulations for milk and dairy products of the Eurasian Economic Union [12], which came into force in January 2020, it is necessary to monitor the somatic cell count (SCC), i.e., the level of somatic cells, in raw milk [12]. For a healthy animal, the number of cells does not exceed 200 thousand cells in $1 \mathrm{~mL}$ of milk sample $\left(2 \cdot 10^{5}\right.$ cells $\left./ \mathrm{cm}^{3}\right)$ from one cow [12]. In contrast, the SCC values in the "raw milk" (so-called "raw material" [13]) must be below $4 \cdot 10^{5}$ cells $/ \mathrm{cm}^{3}$ according to the Russia state standards $[13,14]$, which are still valid.

Somatic milk cells $[15,16]$ are roughly represented by epithelial cells of the mammary glands, alveoli, and small milk ducts; degenerated epithelial cells with a dilapidated structure; and blood cells (lymphocytes, neutrophils, eosinophils, etc.) [17]. Flow cytometry analysis allows differentiating of somatic cell populations in milk [15]. From the practical point of view, the typing of milk leukocytes seems to be the most valuable at farms [16]. This is an important step in understanding the immune response of the udder [16], the immunological biology of milk and mammary glands [17], etc. The number of somatic cells is kept as constant as possible in healthy animals $[16,17]$, whereas the inflammatory process in the udder is accompanied by an increase in the total number of neutrophils and lymphocytes [16].

The somatic cell count (SCC), i.e., the total number of somatic cells in milk, depends on many factors: breed of animals, age, lactation stage, animal health status, and number of calves. As soon as the process of inflammation appears in the udder, SCC values increase sharply by an order of magnitude, and sometimes, even higher. Primary inflammatory processes, even without visible symptoms, can be detected by an increase in the total number of somatic cells. There are only minor changes in milk biochemical parameters observed at so-called "normal" level of somatic cells, whereas the increased SCC values (released due to the inflammatory process) bring the milk uncharacteristic taste and odor. The milk obtained in the last case is not suitable for further processing and often causes distortions in the technological chain of dairy product preparations. In the most serious situations, such milk can directly contain pathogens (staphylococci, etc.), which can infect consumers with some diseases. For example, "mastitis" milk causes food poisoning of bacterial origin, disorders of the gastrointestinal tract, and streptococcal sore throat in adults and, especially, for children.

In this regard, it is of great importance to study the correlations of the main biochemical parameters of cow's milk samples with certain values of the total amount of watersoluble antioxidants (TAWSA). For example, in the work of Arab scientists in 2008 [18], the indicators of the total number of somatic cells and their three types (macrophages, lymphocytes, and polymorphonuclear leukocytes), as well as the antioxidant activity of the following enzymes, catalase, superoxide dismutase, and glutathione peroxidase, were studied in detail. The authors [18] randomly selected 43 cow milk samples (from 8 farms in Tunisia from November 2005 to February 2006). All samples were separated by the authors [18] into three groups in accordance with the number of SCC: less than 1000 thousand units/mL, from 1000 to 1500 thousand units/mL; more than 1500 thousand units/ $\mathrm{mL}$ in comparison to the average over the sum of all samples [18]. The authors [18] found that catalase and glutathione peroxidase correlated at a high degree (about 0.66 ) with both the total number of somatic cells and the number of neutrophils. From a biochemical point of view, the product of the catalase reaction is hydrogen peroxide and a hydroxyl radical [9]; the activity of these enzymes increases precisely to neutralize the negative effect of ROS [18]. In addition, the total activity of these enzymes is one of the most important markers of mastitis in cows [18], i.e., a promising indicator of milk quality and health of cows [18-20].

The major points mentioned above, especially the relationships between the total antioxidant activity and biochemical parameters of cow milk at various somatic cell counts, have been little investigated in all of their complexity.

The aims of the work were the following: to measure the total amount of water-soluble antioxidants and some other biochemical parameters of cow milk depending on the somatic cell count in the whole range of values; to analyze the statistics; and to establish the correlations between the obtained parameters of cow milk.

\section{Materials and Methods}

Milk samples (total amount of 73 units) of black-and-white cows were obtained from farms of the Moscow region during the winter stall period. The experimental protocols (concerning these animals) were approved by the Bioethical Committee of the Federal Research Center for Animal Husbandry named after Academy Member L.K. Ernst. All experiments and conditions (animal care, feeding, biological material sampling, etc.) were fulfilled in accordance with the applicable regulations (internationally recognized guidelines and local acts).

Methods and approaches to the determination and analysis of the main biochemical parameters of cow milk (fat, proteins, lactose, etc.) were described in a large number of 
works [8-14]. In our research, the analytical system MilkoScan 7/Fossomatic 7 DC (Denmark) was used to analyze the component composition of cow's milk and the somatic cell count (SCC). MilkoScan 7 is a spectrophotometer based on Fourier transform infrared spectrophotometry. Fossomatic 7 performs somatic cell counting based on flow cytometry.

The amperometric method [5-7] was used to study the total amount of water-soluble antioxidants (TAWSA). The measurements were carried out on a TsvetYauza 01-AA device $[5,10-12]$. The TAWSA was determined by measuring the strength of the electric current arising during the oxidation of molecules on the surface of the working electrode at a certain potential. The "working solutions" of gallic acid $\left(100 \mathrm{mg} / \mathrm{dm}^{3}\right)$ were used as a standard for measuring the TAWSA of the samples, which is described in detail in [5-7]. Phosphoric acid solution $0.0022 \mathrm{~mol} / \mathrm{dm}^{3}$ was used as an eluent. The flow rate of the eluent to the peristaltic pump is $1.2 \mathrm{~cm}^{3} / \mathrm{min}$. Since the signal from the analyzed milk samples exceeded the signal of the calibration solution $\left(4.0 \mathrm{mg} / \mathrm{dm}^{3}\right.$ gallic acid), the samples were preliminarily diluted $(100 \mu \mathrm{L}$ of the sample plus $1900 \mu \mathrm{L}$ of bidistilled water). At the same time, the key to the reliability and good repeatability of the obtained result was the cleanliness of the working surface of the electrode and reliable calibration at the beginning of each working procedure. The calculation of the mass concentration of antioxidants $(X, \mathrm{mg} / \mathrm{g})$ was performed in equivalent to gallic acid, taking into account the dilution of the sample, according to the following equation [5-7].

$$
X=\frac{\left(X_{G} \cdot N \cdot V_{n}\right)}{\left(m_{n} \cdot 1000\right)},
$$

where $X_{G}$ is the mass concentration of antioxidants (measured in $\mathrm{mg} / \mathrm{L}$ );

$N$ is the dilution factor of the analyzed sample;

$V_{n}$ is the volume of the solution (extract) in the analyzed sample (in $\mathrm{mL}$ );

$m_{n}$ is the sample of the "analyte" (in g).

The results of the general antioxidant activity and the main biochemical parameters of cow's milk were statistically processed using the "Microsoft Excel" program.

\section{Results and Discussion}

Important data on the biochemical composition and antioxidant activity of milk samples from black-and-white cows of the Moscow region in the "winter stall period" were obtained. At the first stage of the analysis, all indicators for 73 milk samples of black-and-white cows from the Moscow region farms were evaluated. The TAWSA values for all milk samples ranged from $6.8 \mathrm{mg} / \mathrm{g}$ to $27.9 \mathrm{mg} / \mathrm{g}$ (mean value $15.43 \pm 3.7 \mathrm{mg} / \mathrm{g}$ ). Relatively weak correlations were found between TAWSA and the following milk parameters for all these samples: total fat percentage (TFP) - 0.27 ; true protein percentage (TP1) and total nitrogen percentage (TN2) - 0.18 (in both cases); lactose - 0.14; solids-not-fat (SNF) 0.14 ; total dry matter (TDM) - 0.28; freezing temperature point $(\mathrm{FP})-0.03 ; \mathrm{pH}-(-0.16)$; the somatic cell counts (SCC) - $(-0.01)$.

At the second stage of the analysis, the TAWSA and the average biochemical parameters were assessed for four groups of cows, which were selected according to the values of the SCC. Such a division was fulfilled in accordance with the requirements of the technical regulations for milk and dairy products of the Eurasian Economic Union and the corresponding Russian state standards and technical requirements [12-14]. That is why four groups were selected according to SCC values: (1) less than 200 thousand units/ $\mathrm{mL}$, (2) from 200 to 499 thousand units/mL, (3) from 500 to 999 thousand units $/ \mathrm{mL}$, and (4) more than 1000 thousand units/mL for milk samples of black-and-white cows of the Moscow region farms (as raw materials).

Group 1 (selected according to SCC values less than 200 thousand units $/ \mathrm{mL}$ ) was the most numerous of the four and included 33 milk samples of black-and-white cows of the Moscow region farms (Table 1).

The TAWSA values of the 33 milk samples of group 1 ranged from $6.80 \mathrm{mg} / \mathrm{g}$ to $27.91 \mathrm{mg} / \mathrm{g}$, and the average value was $15.95 \pm 0.74 \mathrm{mg} / \mathrm{g}$ (Table 1). The correlations between TAWSA and the following parameters of milk were the following: total fat percentage (TFP) -0.305 ; true protein percentage (TP1) -0.197; total nitrogen percentage (TN2) -0.210 ; lactose -0.156 ; solids-not-fat (SNF) -0.276 ; total dry matter (TDM) -0.399; freezing point (FP) -0.112; pH -0.114; somatic cell count (SCC) - $(-0,052)$. Average values were obtained for the following parameters: TFP - 5.16\%; TP1 or TN2 - 3.22\% or 3.45\%; lactose - $4.87 \%$; SNF 9.16\%; TDM - 14.37\%; freezing point $-(-0.540)^{\circ} \mathrm{C} ; \mathrm{pH}-$ 6.57; SCC - about 99 thousand units/mL.

Group 2 (selected according to SCC values from 200 to 499 thousand units $/ \mathrm{mL}$ ) consisted of 15 milk samples of black-and-white cows of the Moscow region farms (Table 2).

The TAWSA values of the 15 milk samples of group 2 ranged from $8.90 \mathrm{mg} / \mathrm{g}$ to $18.99 \mathrm{mg} / \mathrm{g}$, and the average value was $14.45 \pm 0.84 \mathrm{mg} / \mathrm{g}$. The average values obtained for the following parameters: TFP $-4.72 \%(p<0.1$ to group 1$)$; TP1 and TN2-3.26\% and 3.49\%; lactose - 4.80\%; SNF 9.14\%; total dry matter $-13.92 \%(p<0.05$ to group 1$)$; freezing point $-(-0.539)^{\circ} \mathrm{C}$; $\mathrm{pH}-6.53(p<0.05$ to group 1$)$; $\mathrm{SCC}-$ about 333 thousand units $/ \mathrm{mL}$ ( $p<0.01$ to group 1$)$. The correlations between TAWSA and the following parameters of milk were the following: TFP -0.332; TP1-0.296; TN2 0.303 ; lactose - (-0.308); SNF -0.159; TDM -0.391; FP $(-0.226) ; \mathrm{pH}-(-0.211)$; SCC -0.193 .

Group 3 (selected according to SCC values from 500 to 999 thousand units $/ \mathrm{mL}$ ) consisted of 13 milk samples of black-and-white cows of the Moscow region farms (Table 3).

The TAWSA values of the 13 milk samples of the group 3 ranged from $13.60 \mathrm{mg} / \mathrm{g}$ to $22.25 \mathrm{mg} / \mathrm{g}$, and the average value was $16.05 \pm 0.63 \mathrm{mg} / \mathrm{g}$. The average values obtained for the following parameters: TFP - 5.40\%; TP1 and TN2$3.58 \%$ and $3.81 \%$ (for both, $p<0.05$ to group 1); lactose $4.51 \%(p<0.01$ to group 1$)$; SNF $-9.21 \%$; total dry matter - $14.67 \%$; freezing point $-(-0.540)^{\circ} \mathrm{C} ; \mathrm{pH}-6.54$ units; SCC - 805.23 thousand units/mL ( $p<0.01$ to group 1$)$. The correlations between TAWSA and the following parameters of 
TABLE 1: The major biochemical parameters and component composition of milk samples ( $n=33$, group 1).

\begin{tabular}{|c|c|c|c|c|c|c|c|}
\hline Biochemical parameters & Average value & Mean & Min & $\operatorname{Max}$ & $\mathrm{CV}, \%$ & $\mathrm{SD}$ & $\pm \mathrm{m}$ \\
\hline TFP, \% & 5.16 & 4.93 & 3.62 & 7.30 & 15.88 & 0.82 & 0.14 \\
\hline TP1, \% & 3.22 & 3.13 & 2.65 & 4.49 & 12.74 & 0.41 & 0.07 \\
\hline TN2, \% & 3.45 & 3.38 & 2.89 & 4.75 & 11.96 & 0.41 & 0.07 \\
\hline TAWSA mg/g & 15.95 & 16.00 & 6.80 & 27.91 & 26.72 & 4.26 & 0.74 \\
\hline Lactose, $\%$ & 4.87 & 4.90 & 4.51 & 5.32 & 3.98 & 0.19 & 0.09 \\
\hline SNF, \% & 9.16 & 9.11 & 8.24 & 10.80 & 5.38 & 0.49 & 0.09 \\
\hline TDM, \% & 14.37 & 14.11 & 12.68 & 19.93 & 6.90 & 0.99 & 0.17 \\
\hline $\mathrm{FP},{ }^{\circ} \mathrm{C}$ & -0.540 & -0.538 & -0.568 & -0.526 & -1.77 & 0.01 & 0.01 \\
\hline $\mathrm{pH}$, units & 6.57 & 6.56 & 6.47 & 6.84 & 1.07 & 0.07 & 0.01 \\
\hline SCC, $10^{3}$ cells $/ \mathrm{mL}$ & 99.33 & 73 & 27 & 194 & 56.64 & 52.87 & 9.20 \\
\hline
\end{tabular}

TABLe 2: The major biochemical parameters and component composition of milk samples ( $n=15$, group 2 ).

\begin{tabular}{|c|c|c|c|c|c|c|c|}
\hline Biochemical parameters & Average value & Mean & Min & $\operatorname{Max}$ & $\mathrm{CV}, \%$ & SD & $\pm \mathrm{m}$ \\
\hline TFP, $\%$ & 4.72 & 4.84 & 3.61 & 6.00 & 15.44 & 0.73 & 0.19 \\
\hline TP1, \% & 3.26 & 3.31 & 2.60 & 3.78 & 9.00 & 0.29 & 0.08 \\
\hline $\mathrm{TN} 2, \%$ & 3.49 & 3.53 & 2.84 & 4.03 & 8.51 & 0.30 & 0.08 \\
\hline TAWSA mg/g & 14.45 & 14.81 & 8.90 & 18.99 & 22.64 & 3.27 & 0.84 \\
\hline Lactose, $\%$ & 4.80 & 4.79 & 4.28 & 5.23 & 4.51 & 0.22 & 0.06 \\
\hline SNF, \% & 9.14 & 9.14 & 8.36 & 9.63 & 3.55 & 0.32 & 0.02 \\
\hline TDM, \% & 13.92 & 14 & 12.28 & 14.8 & 5.28 & 0.73 & 0.19 \\
\hline $\mathrm{FP},{ }^{\circ} \mathrm{C}$ & -0.539 & -0.541 & -0.556 & -0.519 & -1.91 & 0.01 & 0.00 \\
\hline $\mathrm{pH}$, units & 6.53 & 6.52 & 6.42 & 6.67 & 0.98 & 0.06 & 0.02 \\
\hline $\mathrm{SCC}, 10^{3} \mathrm{cell} / \mathrm{mL}$ & 333.33 & 299 & 208 & 499 & 28.61 & 95.36 & 24.62 \\
\hline
\end{tabular}

TABLE 3: The major biochemical parameters and component composition of milk samples ( $n=13$, group 3).

\begin{tabular}{|c|c|c|c|c|c|c|c|}
\hline Biochemical parameters & Average value & Mean & Min & $\operatorname{Max}$ & $\mathrm{CV}, \%$ & SD & $\pm \mathrm{m}$ \\
\hline TFP, \% & 5.40 & 5.35 & 4.06 & 6.84 & 15.26 & 0.82 & 0.23 \\
\hline $\mathrm{TP} 1, \%$ & 3.58 & 3.49 & 2.48 & 4.57 & 17.32 & 0.62 & 0.17 \\
\hline TN2, \% & 3.81 & 3.72 & 2.71 & 4.81 & 16.66 & 0.64 & 0.18 \\
\hline TAWSA mg/g & 16.05 & 15.40 & 13.60 & 22.25 & 14.12 & 2.27 & 0.63 \\
\hline Lactose, $\%$ & 4.51 & 4.55 & 3.51 & 5.14 & 9.52 & 0.43 & 0.12 \\
\hline SNF, \% & 9.21 & 9.20 & 7.92 & 10.60 & 8.48 & 0.78 & 0.22 \\
\hline TDM, \% & 14.67 & 14.72 & 12.72 & 17.02 & 9.07 & 1.33 & 0.37 \\
\hline $\mathrm{FP},{ }^{\circ} \mathrm{C}$ & -0.540 & -0.544 & -0.55 & -0.519 & -0.78 & 0.01 & 0.01 \\
\hline $\mathrm{pH}$, units & 6.54 & 6.52 & 6.42 & 6.68 & 1.33 & 0.09 & 0.02 \\
\hline SCC, $10^{3} \mathrm{cell} / \mathrm{mL}$ & 805.23 & 903 & 542 & 973 & 19.75 & 159.0 & 44.10 \\
\hline
\end{tabular}

milk were found: MFF - (-0.353); TP1 and TN2 - (-0.411) and (-0.401); lactose - (-0.166); SNF - (-0.472); TDM $(-0.504)$; FP - 0.766; pH - (-0.047); SCC - $(-0.725)$.

Group 4 (selected according to SCC values more than 1000 thousand units/mL) consisted of 12 milk samples of black-and-white cows of the Moscow region farms (Table 4).

The TAWSA values for these milk samples of group 4 ranged from $5.80 \mathrm{mg} / \mathrm{g}$ to $20.30 \mathrm{mg} / \mathrm{g}$ (mean value $14.58 \pm$ $1.18 \mathrm{mg} / \mathrm{g}$ ). The average values obtained for the following parameters: TFP - 5.18\%; TP1 and TN2-3.38\% and 3.61\%
( $p<0.1$ to group 1$)$; lactose $-4.47 \%(p<0.01$ to group 1$)$; SNF - $8.93 \%$ ( $p<0.1$ to group 1$)$; dry matter $-14.20 \%$; freezing point $-0.534^{\circ} \mathrm{C}(p<0.1$ to group 1$) ; \mathrm{pH}-6.52(p<0.1$ to group 1); SCC - 3259 thousand units/mL $(p<0.01$ to group 1 ). The correlations between TAWSA and BC (group 4) were the following: TFP -0.159; TP1-0.100; TN2 - 0.048; lactose - (-0.317); SNF - (-0.237); TDM -0.058; FP - (-0.036); $\mathrm{pH}-(-0.477)$; SCC - (-0.072).

Thus, there are almost maximal (7 from 9) significant correlations between TAWSA and the major milk 
TABLE 4: The major biochemical parameters and component composition of milk samples ( $n=12$, group 4).

\begin{tabular}{|c|c|c|c|c|c|c|c|}
\hline Biochemical parameters & Average value & Mean & Min & Max & $\mathrm{CV}, \%$ & $\mathrm{SD}$ & $\pm \mathrm{m}$ \\
\hline TFP, $\%$ & 5.18 & 4.96 & 3.80 & 6.97 & 17.63 & 0.91 & 0.26 \\
\hline TP1, \% & 3.38 & 3.41 & 2.38 & 4.24 & 16.65 & 0.56 & 0.16 \\
\hline $\mathrm{TN} 2, \%$ & 3.70 & 3.65 & 3.01 & 4.48 & 12.86 & 0.48 & 0.14 \\
\hline TAWSA mg/g & 14.58 & 13.64 & 5.80 & 20.30 & 27.98 & 4.08 & 1.18 \\
\hline Lactose, $\%$ & 4.47 & 4.55 & 3.63 & 5.04 & 9.32 & 0.42 & 0.12 \\
\hline SNF, \% & 8.93 & 8.88 & 8.44 & 9.79 & 4.82 & 0.43 & 0.12 \\
\hline TDM, \% & 14.20 & 14.05 & 12.71 & 16.27 & 6.11 & 0.87 & 0.25 \\
\hline $\mathrm{FP},{ }^{\circ} \mathrm{C}$ & -0.530 & -0.537 & -0.554 & -0.517 & -2.24 & 0.01 & 0.01 \\
\hline $\mathrm{pH}$, units & 6.52 & 6.53 & 6.36 & 6.65 & 1.30 & 0.09 & 0.02 \\
\hline SCC, $10^{3} \mathrm{cell} / \mathrm{mL}$ & 3259.11 & 2614 & 1004 & 7493 & 64.89 & 2115 & 705 \\
\hline
\end{tabular}

parameters for group 3 (i.e., 3 strong, 4 moderate, 1 relatively weak, 1 weak). There are 5 moderate and 4 relatively weak correlations (from 9 total) between TAWSA and the major milk parameters for group 2. There are only 3 or 2 moderate, 5 or 2 relatively weak, and 1 or 5 weak correlations between TAWSA and the major milk parameters for groups 1 or 4 , respectively. As shown in our previous publications on the study of correlations between TAWSA and biochemical parameters of animal blood [7, 21], positive or negative values of correlations are not as important as their absolute values. These correlations can be very strong (0.75-0.99), strong (0.50-0.74), moderate (0.25-0.49), or weak (0.01-0.24) according to their absolute values [21]. In the last case (weak correlations), it makes sense to discuss only correlations above 0.1 (i.e., from 0.10 to 0.25 ) that can be informally assigned as "relatively weak." For example, moderate $(-0.308)$ or relatively weak $(-0.166)$ correlations between TAWSA and such biochemical parameter as lactose were found for groups 2 or 3 , respectively. The most important correlations (in the case of cow milk) between TAWSA and such biochemical parameters as total fat, true protein and total nitrogen percentages were found for group 2 (or group 3), i.e., TFP -0.332 (or -0.352 ); TP1 and TN2 -0.296 (or -0.411) and 0.303 (or -0.401), respectively. It is important to highlight the strong correlations between TAWSA and such biochemical parameters as total dry matter; freezing point and somatic cell count were found only in the case of group 3, i.e., TDM - (-0.504); FP - (-0.766) and SCC $(-0.725)$, as well as moderate correlation between TAWSA and SNF - (-0.472).

It is well-known that an increased SCC values lead to some changes in the chemical composition of milk, for example, a decrease in titration acidity and an increase of the milk $\mathrm{pH}$. These effects can lead to a change in the redox potential of milk [22]. However, in our study, the $\mathrm{pH}$ practically did not change and remained in the range from 6.57 (group 1) to 6.53 (groups 2 and 3) and 6.52 (group 4). From a practical point of view, it is important to check a relationship between a milk yield and the content of somatic cells in the case of each of the group, mentioned above. Usually in this case, the milk yield of cows is significantly reduced [23]. We found that for the cow groups 1-4, the milk yield values were the following: $22.9 \pm 5.9 \mathrm{~L}, 20.7 \pm 7.8 \mathrm{~L}, 17.9 \pm$
$8.8 \mathrm{~L}$, and $19.3 \pm 8.9 \mathrm{~L}$, respectively. When analyzing the milk yield by these groups, one can observe a gradual decrease in the amount of milk yield by increasing the number of somatic cells. In addition, the correlations between TAWSA and the milk yield values were the following: $-0.325,-0.136,-0.107$, and -0.144 . Thus, only a moderate correlation between milk yield and SCC was found in the case of the group $1(-0.325)$, while only weak negative correlations were found for groups 2-4.

It is important to highlight that in the literature, there is only a single indication of the correlation between total antioxidant activity (determined by another method) and the total milk yield throughout the large herd with a coefficient of -0.22 [24]. This value (-0.22) [24] corresponds, in general, to our abovementioned correlations by sign and number when averaged over all groups. Moreover, in the case of group 1, we found significantly higher correlations between the values of TAWSA and average milk yield, which confirmed the importance of limiting the SCC number below 200 thousand units/mL.

All correlations mentioned above (especially the strong and moderate), will give valuable information for future prognosis of milk technological properties and quality in addition to the standard values.

\section{Conclusions}

From the abovementioned results, it is possible to distinguish not only the contribution of each indicator to the milk raw materials but also the correlations between TAWSA and the component composition of cow's milk (revealed for the first time). It is important to highlight the strong and moderate correlations found between TAWSA and the majority of the biochemical parameters in the case of groups 1-3. The weakest correlation between TAWSA and most of the above parameters of cow milk found for group 4 could be associated with the maximum SCC values.

Taking into account that the absolute values of the majority of biochemical and physical-chemical parameters of milk do not change significantly (even nonlinearly) with an increase in the SCC values, the obtained correlation coefficients can be an important element of milk research. These data complement with the known models and can be useful 
for a more detailed analysis of animal milk, assessment of the animal physiological and biochemical status, and dairy product quality.

\section{Data Availability}

The data supporting the reported results can be found at https://www.vij.ru/institut/struktura-organizatsii/nauchnyepodrazdeleniya/52-gruppa-analiticheskoj-biohimii.

\section{Conflicts of Interest}

The authors declare that there is no conflict of interest regarding the publication of this paper.

\section{Acknowledgments}

The technical support of Kolesnik N.S. and Plotnikov D.D. is recognized. This research is supported by the Ministry of Science and Higher Education of the Russian Federation, State Task Topic of the Year 2021 (registration number 121052600314-1).

\section{Supplementary Materials}

Supplementary Materials will be mentioned as Tables S1-S4. (Supplementary Materials)

\section{References}

[1] B. Halliwell, J. Halliwell, and M. C. Gutteridge, Free Radicals in Biology and Medicine, Oxford University Press, 2015.

[2] T. Bohn, "Carotenoids and markers of oxidative stress in human observational studies and intervention trials: implications for chronic diseases," Antioxidants, vol. 8, no. 6, p. 179, 2019.

[3] Y. I. Yashin, V. Y. Ryzhnev, A. Y. Yashin, and N. I. Chernousova, Natural Antioxidants. Content in Food and Their Impact on Human Health and Aging, Moscow, Publishing house TransLit, in Russian, 2009.

[4] Y. P. Fomichev, L. A. Nikanova, V. I. Dorozhkin et al., Dihydroquercetin and Arabinogalactan - Natural Bioregulators in Human and Animal Life, Use in Agriculture and Food Industry, Monograph M: Scientific library, in Russian, 2017.

[5] A. Ya, Journal of the Russian Chemical Society named after D. I. Mendeleev, vol. XLVI, no. 4, pp. 109-115, 2020.

[6] A. A. Savina, "Amperometric detection of antioxidant activity of model and biological fluids," Bulletin of Moscow University. Series 2: Chemistry, vol. 58, no. 2, pp. 97-103, 2020.

[7] S. Y. Zaitsev, A. A. Savina, A. A. Volnin, O. A. Voronina, and N. V. Bogolyubova, "Comparative study of the water-soluble antioxidants in fodder additives and sheep blood serum by amperometric and biochemical methods," Animals, vol. 10, no. 7, p. 1186, 2020.

[8] E. A. Yurova, Investigation of the Influence of the Composition and Properties of Raw Milk on the Quality of Dairy Products, Diss. Ph.D. Moscow, in Russian, 2012.

[9] S. Y. Zaitsev, Biological Chemistry: From Biologically Active Substances to Organs and Tissues of Animals, ZAO "Capital Print”, Moscow, 2017.
[10] S. Y. Zaitsev, Tensiometric and Biochemical Analysis of Animal Blood: Fundamental and Applied Aspects. Monograph, M: Publishing house Agricultural technologies, in Russian, 2016.

[11] S. Y. Zaitsev, O. A. Voronina, N. A. Dovzhenko, I. V. Milaeva, and M. S. Tsarkova, "Comprehensive analysis of the colloid biochemical properties of animal milk as complex multicomponent system," BioNanoScience, vol. 7, no. 1, pp. 26-31, 2017.

[12] TR 033/2013 (Actual Since 09.10.2013) Technical Regulations of the Customs Union, On the safety of milk and dairy products, as amended on 10.07.2020 Moscow in Russian, 2013.

[13] GOST R 52054-2003 (valid since 01 012004), Fresh Cow's Milk - Raw Material Specifications, in Russian, 2003.

[14] GOST R 54761-2011 (actual since 0101 2013) Milk and dairy products, Methods for Determining the Proportion of Dry Skim Dairy Residue Mass Fraction, in Russian, 2011.

[15] C. Pipino, D. Mandatori, F. Buccella et al., "Identification and characterization of a stem cell-like population in bovine milk: a potential new source for regenerative medicine in veterinary," Stem Cells and Development, vol. 27, no. 22, pp. 1587-1597, 2018.

[16] A. Zecconi, L. Zanini, M. Cipolla, and B. Stefanon, "Factors affecting the patterns of total amount and proportions of leukocytes in bovine milk," Animals, vol. 10, no. 6, p. 992, 2020.

[17] P. Rainard, G. Foucras, D. Boichard, and R. Rupp, “_Invited review:_ low milk somatic cell count and susceptibility to mastitis," Journal of Dairy Science, vol. 101, no. 8, pp. 6703-6714, 2018.

[18] H. Hamed, A. El Feki, and A. Gargouri, "Total and differential bulk cow milk somatic cell counts and their relation with antioxidant factors," Comptes Rendus Biologies, vol. 331, no. 2, pp. 144-151, 2008.

[19] S. Y. Zaitsev, N. V. Bogolyubova, X. Zhang, and B. Brenig, "Biochemical parameters, dynamic tensiometry and circulating nucleic acids for cattle blood analysis: a review," PeerJ, vol. 8, p. e8997, 2020.

[20] K. K. Gorbatova and P. I. Gun'kova, Biochemistry of Milk and Dairy Products, S.-Petersburg: Publishing house “GIORD”,, in Russian, 4th edition, 2010.

[21] S. Yu, "Dynamic surface tension measurements as general approach to the analysis of animal blood plasma and serum," Advances in Colloid and Interface Science, vol. 235, pp. 201213, 2016.

[22] T. A. Malik, M. Mohini, S. H. Mir et al., "Somatic cells in relation to udder health and milk quality-a review," Journal of Animal Health and Production, vol. 6, no. 1, pp. 18-26, 2018.

[23] V. G. Skopychev, Mastitis: Etiology, Physiology, Prevention, Diagnosis and Treatment, S.-Petersburg: Publishing House "StPSAVM", in Russian, 2017.

[24] G. Niero, M. Penasa, A. Costa et al., "Total antioxidant activity of bovine milk: phenotypic variation and predictive ability of mid-infrared spectroscopy," International Dairy Journal, vol. 89, pp. 105-110, 2019. 